\title{
BMJ Open Population-based study on the prevalence and clinical profile of adults with cerebral palsy in Northern Ireland
}

\author{
Karen McConnell (D , ${ }^{1}$ Emma Livingstone, ${ }^{2}$ Oliver Perra, ${ }^{1} \mathrm{C}$ Kerr ${ }^{1}$
}

To cite: McConnell $\mathrm{K}$, Livingstone E, Perra 0, et al. Population-based study on the prevalence and clinical profile of adults with cerebral palsy in Northern Ireland. BMJ Open 2021;11:e044614. doi:10.1136/ bmjopen-2020-044614

- Prepublication history for this paper is available online. To view these files, please visit the journal online (http://dx.doi org/10.1136/bmjopen-2020044614).

Received 08 September 2020 Revised 10 December 2020 Accepted 15 December 2020
Check for updates

(c) Author(s) (or their employer(s)) 2021. Re-use permitted under CC BY-NC. No commercial re-use. See rights and permissions. Published by BMJ.

${ }^{1}$ School of Nursing and Midwifery, Queen's University Belfast, Belfast, UK

${ }^{2}$ Adult Cerebral Palsy Hub, London, UK

Correspondence to Dr C Kerr; c.kerr@qub.ac.uk

\section{ABSTRACT}

Objectives This study aimed to report the prevalence and clinical characteristics of adults with cerebral palsy (CP) in a geographically defined region of the UK.

Design and setting Cross-sectional study using the Northern Ireland Cerebral Palsy Register (NICPR).

Participants All validated cases known to the NICPR, born 1981-2001 and alive and resident in Northern Ireland at age 19 years were included.

Results The study included 1218 persons with CP aged $19-39$ years, 46 of whom died in adulthood. The prevalence of CP was 2.38 per 1000 . The majority of cases had spastic CP ( $\mathrm{n}=1132 / 1218,93 \%)$ and could walk $(n=949 / 1218,78 \%)$. Those that died in adulthood typically had bilateral spastic CP $(n=39 / 46)$ and used a wheelchair $(n=40 / 46)$.

Conclusion The prevalence of CP in adults is similar to other common neurological conditions such as multiple sclerosis and Parkinson's disease. The needs of adults with CP vary widely with almost half having two or more associated impairments that may require multiprofessional and multiagency coordination. Results from this study can be used to inform transformation of health and care services for adults with $\mathrm{CP}$.

\section{INTRODUCTION}

Cerebral palsy $(\mathrm{CP})$ is a complex condition that requires access to a range of health and social care services across the lifespan. While CP is not progressive, ${ }^{1}$ clinical features of the condition can change over time. Recent research has demonstrated that adults with $\mathrm{CP}$ experience secondary comorbidities and quicker declining mobility when compared with the general population. ${ }^{23}$ In addition, many adults with CP experience pain, ${ }^{2-5}$ depression and anxiety, ${ }^{6}$ and are more likely to develop other chronic conditions, such as asthma, stroke, heart disease and arthritis. ${ }^{78}$ Coupled with this, an increasing number of severely impaired young people with CP are now surviving and transitioning to adult services. ${ }^{9}$ This highlights the importance of providing comprehensive health and social care services that address the many and varying needs of adults with CP.

\section{Strengths and limitations of this study}

This study used a population-based cerebral palsy register that uses multiple sources of ascertainment.

- Northern Ireland Cerebral Palsy Register data are collected during childhood and thus results are an estimate of the condition in adulthood.

Data were only available for those aged under 40 years.

Research in CP has primarily focused on management of children with the condition, but there is now an increased focus on adults with CP. In 2019, the National Institute for Health and Care Excellence (NICE) published clinical guidelines for adults with CP. ${ }^{10}$ More recently NICE published quality standards, setting out five key areas for quality improvement in health services for adults with $\mathrm{CP} .{ }^{11}$ Implementation of such guidelines and quality standards is expected to increase quality of life and functional independence, decrease pain, improve participation and reduce unplanned hospital admissions. ${ }^{11}$ However, current services in the UK fall short of these standards, with NICE recently reporting that service provision for adults with $\mathrm{CP}$ is insufficient and lacks continuity of care. ${ }^{10}$ In order to develop and transform services for adults with CP, it is important to quantify the number and needs of the population that will use such services.

The Northern Ireland Cerebral Palsy Register (NICPR) is a cross-sectional, population-based register of people with CP in Northern Ireland born since 1977. Data are collected in childhood. The NICPR aims to monitor trends in the prevalence of the condition, provide a framework for research and provide reliable information for service planners and providers regarding the needs of people living with CP in Northern Ireland. ${ }^{12}$ Jonsson et al recently demonstrated that more severe CP types such as spastic tetraplegia and dyskinesia are less common in adults 
than children. ${ }^{13}$ While the profile of the CP population in adulthood may be different to that of childhood, data from the NICPR provides population-based estimates of numbers and abilities of persons with $\mathrm{CP}$ and thus are useful for planning care and services.

The purpose of this study was to provide information on the prevalence and functional abilities of adults with CP born from 1981 to 2001, who were alive and resident in Northern Ireland at the time of transitioning to adult services, that is, at 19 years of age. Specifically, this study aimed to report the prevalence and clinical characteristics of adults aged 19-39 years with CP in one region of the UK to help inform health and social care services planning and delivery more generally.

\section{METHOD}

\section{Study design and eligibility}

This population-based cross-sectional study included all validated cases of CP (congenital and acquired) known to the NICPR born between 1981 and 2001 and alive and resident in Northern Ireland at age 19 years. The sample thus constitutes all adults known to the NICPR from the register's first fully ascertained birth year (1981 birth cohort, aged 39 years old) through to those who have just moved from paediatric services (2001 birth cohort, aged 19 years). Those who died, or moved out of the region before the age of 19 years, were excluded from the sample.

\section{Method of the NICPR}

At inception, the NICPR used Mutch $e t a l$ 's definition of $\mathrm{CP}^{14}{ }^{4}$ The definition by Rosenbaum et al has been employed since 2007. ${ }^{1}$ The NICPR adheres to Surveillance of Cerebral Palsy in Europe (SCPE) guidelines and processes regarding eligibility and classification of cases. ${ }^{15}$ Reliability of the NICPR is demonstrated by multiple ascertainment and notification of cases by healthcare professionals including paediatricians, physiotherapists, occupational therapists and families. In addition, routine searches of special education schools and hospital inpatient admission lists help to maximise case ascertainment. Each notified case is followed up with a standardised assessment booklet, completed by a clinician well known to the child, detailing the birth history, clinical characteristics of the child's condition and any additional medical conditions. ${ }^{16}$ After the child's fourth birthday, all assessment booklets are reviewed by the Register's paediatrician to confirm or refute diagnosis of CP. Children who die before the age of 2 years, or who emigrate before the age of 3 years, are excluded from the NICPR. Annual information on deaths and emigration is received from the Northern Ireland Health and Social Care Business Services Organisation.

\section{Study variables}

CP subtype was classified according to the SCPE definitions as spastic bilateral, spastic unilateral, dyskinetic, ataxic and unclassifiable. ${ }^{15}$ Gross motor function was classified using the Gross Motor Function Classification System (GMFCS) ${ }^{17}$ For cases predating publication of the GMFCS an algorithm was applied to registry data, the validity of which was found to be satisfactory. ${ }^{18}$ Upper limb function was rated using a 4-level system from I (no problem) to IV (incapable of eating/dressing). Hearing, visual, communication and intellectual impairments were reported as being present, not present or uncertain. Feeding problems were coded from free-text comments as present (eg, being fed via nasogastric tube, percutaneous endoscopic gastrostomy in situ, fed orally with difficulties or gastro-oesophageal reflux) or not present. Seizures, excluding neonatal and febrile seizures, were reported as ever having occurred, never having occurred or uncertain.

\section{Statistical analysis}

The prevalence rate of CP for those born from 1981 to 2001 was calculated per 1000 population of the same age using the Northern Ireland Statistics and Research Agency's midyear population estimates. Descriptive statistics were used to summarise clinical characteristics and functional ability of the sample. All statistical analyses were performed using STATA (V.12.0; StataCorp). In order to identify and summarise definite clinical needs, associated impairments were dichotomised as present or not present/uncertain.

\section{Patient and public involvement}

Mrs Emma Livingstone (Adult CP Hub) was involved at all stages of the study and is coauthor of the paper.

\section{RESULTS}

Of the 1369 cases born 1981-2001 (ie, aged 19-39) and known to the NICPR, 151 were excluded because they had died $(n=113)$ or moved out $(n=38)$ before the age of accessing adult services (19 years old). Of those who died before transitioning to adult services, 93\% ( $\mathrm{n}=105 / 113)$ were classified as GMFCS levels IV-V and $86 \%(n=97 / 113)$ had experienced seizures in the past. Mean age of death was 10 years (range 2-19 years). Those who moved out of the region prior to transitioning were comparable to the sample included in this study, with more than twothirds $(68 \%, 26 / 38)$ classified as GMFCS levels I-III. A total of 1218 persons with CP aged 19-39 years were thus included, 93\% ( $\mathrm{n}=1137 / 1218)$ of whom were still alive and resident in Northern Ireland at the time of this study. The remaining $7 \%(\mathrm{n}=81 / 1218)$ either died $(\mathrm{n}=46)$ or moved out $(n=35)$ after accessing adult services (figure 1). Latest figures from the Northern Ireland Statistics and Research Agency estimated the total population of persons aged 19-39 years old, living in Northern Ireland in 2019, to be 511261.

\section{Prevalence and clinical characteristics of persons with CP born 1981-2001 (aged 19-39 years)}

The period prevalence of CP (1981-2001) was 2.38 per 1000 population born during the same period. This rate 


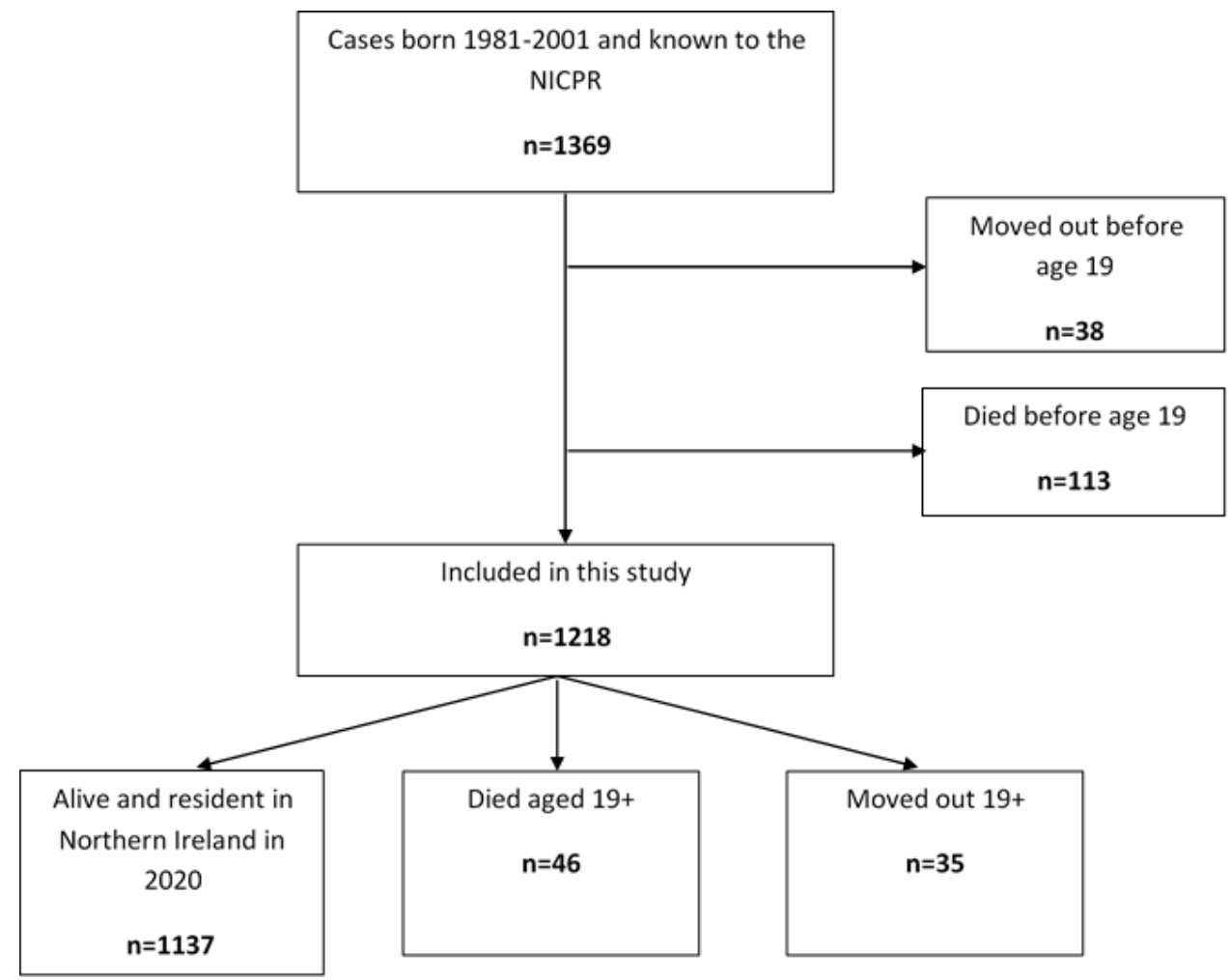

Figure 1 Flow diagram showing inclusion of participants born during 1981-2001. NICPR, Northern Ireland Cerebral Palsy Register.

includes those who transitioned to adult services but have since died or emigrated.

This population-based sample of adults with CP aged $19-39$ years, were $56 \%$ male $(n=683 / 1218)$. The majority of cases had spastic CP ( $n=1132 / 1218,93 \%)$, with $47 \%$ of those being unilaterally affected $(\mathrm{n}=535 / 1132)$ and $53 \%$ having bilateral involvement $(n=597 / 1132)$. More than three-quarters of the sample could walk independently or with the use of a walking aid (GMFCS levels I-III, $n=949 / 1218,78 \%)$. The majority of the sample $(\mathrm{n}=833 / 1218,68 \%)$ had at least one reported associated impairment and almost 15\% ( $\mathrm{n}=177 / 1218)$ had four or more reported associated impairments. Additional information relating to upper limb function and associated impairments can be found in table 1 .

Of the 46 cases with CP that died after transitioning to adult services, the majority were male $(n=30 / 46,65 \%)$. All cases died between 19 and 35 years $(\mathrm{n}=24$ aged $<25$ years, $\mathrm{n}=22$ aged $25-35$ years), the majority had bilateral spastic CP $(n=39 / 46,85 \%)$ and were classified as GMFCS levels IV-V $(n=40 / 46,87 \%)$. Underlying cause of death (International Classification of Diseases 10th Revision (ICD-10 version): 2019) ${ }^{19}$ was specified as CP in almost half of cases $(21 / 46,47 \%)$. In the remaining cases, cause of death was categorised from the following ICD-10 categories: malignant neoplasms, epilepsy, congenital malformations, other ill-defined and unspecified causes, surgical operation with formation of external stoma, and diseases of the circulatory, respiratory, digestive and genitourinary systems. More granular data cannot be presented as none of these ICD-10 categories were notified for more than five deaths.

\section{DISCUSSION}

This population-based study reported the prevalence and clinical characteristics of persons with CP born 19812001 in one region of the UK. It thus represents a cohort of younger adults (aged 19-39 years) with CP that require ongoing coordination and management of their condition within adult health and social care services. More than $90 \%$ of children with CP notified to the NICPR survived, or remained in the region and thus transitioned from paediatric to adult services. Four per cent of cases in this study died in adulthood. The period prevalence of CP for 19-39year olds was 2.38 per 1000 population. The majority of cases had spastic CP. Almost a quarter of the population used a wheelchair (GMFCS levels IV-V) and almost one-third required assistance to eat and/or dress or were incapable of eating/dressing themselves. More than one-third of cases reported a history of seizures, or communication, or intellectual impairments. Over $25 \%$ had some form of visual impairment with smaller numbers reporting hearing impairment or feeding difficulties. However, $68 \%$ of cases experienced at least one associated impairment, with almost $15 \%$ experiencing four or more associated impairments. Those with multiple impairments were considered to have complex healthcare needs. This highlights the diverse range of services required for adults with $\mathrm{CP}$. 
Table 1 Characteristics of persons with $\mathrm{CP}$ born during 1981-2001 $(n=1218)$

\begin{tabular}{ll} 
Population characteristics & $\begin{array}{l}\mathbf{1 9 8 1 - 2 0 0 1}(\mathbf{n = 1 2 1 8}) \\
\text { Frequency }(\%)\end{array}$ \\
\hline Sex & \\
\hline Male & $683(56.08)$ \\
Female & $535(43.92)$
\end{tabular}

CP subtype

\begin{tabular}{|c|c|}
\hline Spastic bilateral & 597 (49.01) \\
\hline Spastic unilateral & 535 (43.92) \\
\hline Dyskinetic & $38(3.12)$ \\
\hline Ataxic & 36 (2.96) \\
\hline Unclassifiable & $7(0.57)$ \\
\hline Missing & $5(0.41)$ \\
\hline \multicolumn{2}{|l|}{ GMFCS level } \\
\hline I & $211(17.32)$ \\
\hline II & $614(50.41)$ \\
\hline III & $124(10.18)$ \\
\hline IV & $87(7.14)$ \\
\hline V & $178(14.61)$ \\
\hline Missing & $4(0.33)$ \\
\hline
\end{tabular}

UL function

\begin{tabular}{lc}
\hline No problem & $389(31.94)$ \\
\hline Some difficulty & $443(36.37)$ \\
\hline Needs help eat/dress & $208(17.08)$ \\
\hline Incapable eat/dress & $157(12.89)$ \\
\hline Missing & $21(1.72)$ \\
\hline Seizures & \\
\hline Ever & $426(34.98)$ \\
\hline Never/Uncertain & $681(55.91)$ \\
\hline Missing & $111(9.11)$ \\
\hline Communication & \\
\hline Yes & $465(38.18)$ \\
\hline No/uncertain & $741(60.84)$ \\
\hline Missing & $12(0.99)$ \\
\hline Intellectual & \\
\hline Yes & $490(40.23)$ \\
\hline No/uncertain & $709(58.21)$ \\
\hline Missing & $19(1.56)$ \\
\hline Hearing & \\
\hline Yes & $81(6.78)$ \\
\hline No/Uncertain & $1114(93.22)$ \\
\hline Missing & $23(1.89)$ \\
\hline Vision & \\
\hline Yes & $334(27.42)$ \\
\hline No/uncertain & $879(72.17)$ \\
\hline Missing & $5(0.41)$ \\
\hline
\end{tabular}

Continued
Table 1 Continued

\section{Population characteristics}

1981-2001 ( $\mathrm{n}=1218)$ Frequency (\%)

Feeding

Yes

196 (16.09)

No

$951(78.08)$

Missing

$71(5.83)$

Frequency of associated impairments*

\begin{tabular}{ll}
0 & $385(31.6)$ \\
1 & $285(23.40)$ \\
2 & $184(15.11)$ \\
3 & $187(15.35)$ \\
4 or more & $177(14.53)$ \\
\hline
\end{tabular}

Uncertain: clinician was uncertain as to whether the impairment was present or absent, proportion of cases with data coded as uncertain ranged from $1.56 \%$ for communication impairment to $7.14 \%$ for hearing impairment.

*Frequency of associated impairments included only those impairments reported in the table.

CP, cerebral palsy; GMFCS, Gross Motor Function Classification System; UL, upper limb.

The prevalence of CP in adults aged 19-39 years in this study was 2.38 per 1000 population the same age, which is considerably higher than the rate of 1.14 per 1000 population recently reported in Sweden. ${ }^{13}$ However, the Swedish study included older adults aged $39-58$ years and those who were alive and resident at the time of the study. In comparison, reliable data were not available for those older than 39 years in the current study and the prevalence rate included those who were alive and resident at 19 years, in order to estimate health and social care needs at the time of transition to adult services. This finding highlights the value of population-based CP registers in quantifying the size of the adult CP population in order to inform relevant health and social care services. While results from this study can be applied to other developed countries with similar healthcare systems, there would be added value in other long-standing $\mathrm{CP}$ registers estimating prevalence of $\mathrm{CP}$ in adults.

While the current study included all cases of CP that were alive and resident at the time of transition, that is, 19 years, almost $4 \%$ of cases died after transition to adult services. Not surprisingly, the majority of those who died after the age of 19 years had bilateral spastic CP and were classified as GMFCS levels IV-V, thus necessitating significant resources and services during their time in adult services. This finding is supported by a recent Australian study that demonstrated an increase over time in the number of severely impaired young people with CP surviving and transitioning to adult services. ${ }^{9}$ Data from population-based registers can be used to help plan for future health and social care services for those with more severe CP that may require a broad range of specialised services. 
Findings from this study estimated the clinical profile of adults with CP aged 19-39 years. Comparable to previous population-based reports, the majority of cases had spastic CP. ${ }^{1320}$ Almost a quarter of cases were classified as requiring a wheelchair, considerably more than the $12 \%-15 \%$ of adults with CP reported in previous studies. ${ }^{1320}$ This is potentially due to differences in registry methods for classifying gross motor function. In addition, the current study reported seizures in more than one third of cases while previous reports ranged from $14 \%$ to $19 \% .{ }^{1320}$ Again, this can be explained by differences in defining seizures, whereby we included any history of seizures whereas others included only those cases having treatment or recurring seizures at the time of inclusion on the Register. Alternatively, examination of cases that died before transitioning to adult services revealed that the majority ( $n=93 / 113)$ had experienced seizures in the past 12 months, suggesting epilepsy may be a risk factor for mortality. Our findings highlight the importance of using consistent terminology and definitions to facilitate comparisons between countries and regions.

Recent NICE guidelines ${ }^{10}$ identified the need for the development of pathways that allow adults with CP to access a comprehensive local network of care. Results from this study inform service commissioners and providers about the varied healthcare needs of this population as almost half of cases reported at least two associated impairments. CP is a common neurological condition that requires access to services similar to other neurological conditions. The prevalence of CP in adulthood reported here (2.38 per 1000) is not dissimilar to that reported for multiple sclerosis (1.90 per 1000 population $)^{21}$ or Parkinson's disease (2.85 per 1000 population), ${ }^{22}$ yet health and care services for adults with CP are less well established than those for other neurological conditions, not equitable across regions and fall short of the provision recommended in current guidelines ${ }^{10}$ and standards. ${ }^{11}$

The needs of people with CP are diverse and, like the general population, will change with age, and thus childhood data may not accurately reflect characteristics of adults with CP. For example, adults with the condition experience a decline in mobility earlier than their nondisabled peers ${ }^{23}$ and have increased risk of noncommunicable disease, such as cardiac and respiratory diseases. ${ }^{24}$ The NICE guidelines committee suggests that, dependent on local pathways of care, support for adults with CP may be adequately provided in primary care settings, with regular review. ${ }^{25}$ Specialist input is required if the clinical impact of the condition becomes more challenging for the individual with $\mathrm{CP}$ or if a procedure is being considered that will impact on the execution of usual daily activities. Ensuring that a local pathway is in place will enable access to services for adults with $\mathrm{CP}$ at a local level. ${ }^{10}$ This may help reduce loss of function, morbidity and mortality, ${ }^{13}$ and thus may be more cost-efficient for service providers in the long term. Similarly, a clear pathway for specialist referral, when required, would be of benefit to both general practitioners, who may be the first point of contact, and adults with CP.

Given that findings from this study are based on clinical assessment in childhood, future population-based research is required to more accurately establish functional ability, as well as educational attainment and employment status in adults with CP. In tandem with this, research is needed to further understand current provision of services for adults with $\mathrm{CP}$ and satisfaction with such services. Finally, given that the needs of adults with CP are not well understood, ${ }^{9}$ research is warranted to quantify unmet needs in this population. Research in these areas is urgently required and would further support transformation of care in adults with CP.

The main strength of this study was its use of the population-based register. Reliability of the NICPR is demonstrated by multiple ascertainment of cases, including healthcare professionals and secondary searches of routine health and education systems. However, the NICPR is cross-sectional in nature and provides a snapshot of the condition in childhood. Adults with CP experience quicker declining mobility compared with the general population, ${ }^{23}$ and those able to walk independently as a child may require a wheelchair as an adult. Therefore, these results only provide an estimate of the clinical profile of adults with CP and may overestimate the functional status of adults with CP. In addition, data were not available for adults with $\mathrm{CP}$ over the age of 39 years as the earliest reliable birth cohort available on the NICPR is 1981. Several variables included in this study, namely seizures and feeding, had missing information for more than $5 \%$ of cases. Further, the reliability of clinician reported data on associated impairments is not known, however, this is method is typically used internationally across registry research programmes. ${ }^{15}$ Finally, results of this study are specific to a geographical region of the UK and thus may not be comparable to other regions.

\section{CONCLUSIONS}

Findings from this study highlight that population-based registers can be used to quantify the number and needs of adults with CP. The prevalence of CP in adults is comparable to other common neurological conditions. Adults with CP have complex and varied needs that can change over time, and thus require access to a diverse range of health and care services. Results from this study can be used to inform and transform health and care services for adults with CP.

Twitter Karen McConnell @KMcConnelIQUB and Oliver Perra @oliver_perra

Acknowledgements The authors would like to acknowledge the contributions of Dr Jackie Parkes, Dr Nan Hill, Professor Helen Dolk, Professor Mary-Jane Platt and Dr Cliona Cummings to the NICPR. We thank the NICPR Advisory Committee members, past and present, for their time and commitment to the register. The contributions of the NICPR Public Involvement Group and all the families, children and young people who have taken part in the NICPR are gratefully acknowledged. We thank the Public Health Agency Northern Ireland for their continued funding. 
Contributors KM developed the paper proposal, carried out data analysis and interpretation of findings and drafted the manuscript. EL assisted with development of the paper proposal and critically reviewed the manuscript. OP co-manages the Northern Ireland Cerebral Palsy Register, assisted with development of the paper proposal and critically reviewed the manuscript. CK co-manages the Northern Ireland Cerebral Palsy Register, assisted with development of the paper proposal, contributed to interpretation of findings and drafting the manuscript. All authors approved the final version of the manuscript.

Funding The Northern Ireland Cerebral Palsy Register is funded by the Public Health Agency Northern Ireland (previously Department of Health, Social Services and Public Safety).

Competing interests None declared.

Patient consent for publication Not required.

Ethics approval The NICPR has been approved by the Office for Regional Ethics Committee in Northern Ireland (REC reference 18/NI/0180). The NICPR is governed by an Advisory Committee with representatives from all Health and Social Care Trusts in Northern Ireland, a voluntary sector organisation, an adult with CP and parent representative. The NICPR has a Public Involvement Group, made up of people with $\mathrm{CP}$, their families and carers, which aims to involve the public in all aspects of NICPR activities.

Provenance and peer review Not commissioned; externally peer reviewed.

Data availability statement Data are available on reasonable request. The data used and/or analysed during the current study are available from the corresponding author on reasonable request.

Open access This is an open access article distributed in accordance with the Creative Commons Attribution Non Commercial (CC BY-NC 4.0) license, which permits others to distribute, remix, adapt, build upon this work non-commercially, and license their derivative works on different terms, provided the original work is properly cited, appropriate credit is given, any changes made indicated, and the use is non-commercial. See: http://creativecommons.org/licenses/by-nc/4.0/.

ORCID iD

Karen McConnell http://orcid.org/0000-0002-5221-9800

\section{REFERENCES}

1 Rosenbaum P, Paneth N, Leviton A, et al. A report: the definition and classification of cerebral palsy April 2006. Dev Med Child Neurol Suppl 2007;109:8-14.

2 Lomax MR, Shrader MW. Orthopedic conditions in adults with cerebral palsy. Phys Med Rehabil Clin N Am 2020;31:171-83.

3 Mudge S, Rosie J, Stott S, et al. Ageing with cerebral palsy; what are the health experiences of adults with cerebral palsy? A qualitative study. BMJ Open 2016;6:e012551.

4 van Gorp M, Hilberink SR, Noten S, et al. Epidemiology of cerebral palsy in adulthood: a systematic review and meta-analysis of the most frequently studied outcomes. Arch Phys Med Rehabil 2020;101:1041-52.

5 van der Slot WMA, Benner JL, Brunton L, et al. Pain in adults with cerebral palsy: a systematic review and meta-analysis of individual participant data. Ann Phys Rehabil Med 2020. doi:10.1016/j. rehab.2019.12.011. [Epub ahead of print: 13 Feb 2020].

6 Smith KJ, Peterson MD, O'Connell NE, et al. Risk of depression and anxiety in adults with cerebral palsy. JAMA Neurol 2019;76:294-300.
7 Ryan JM, Allen E, Gormley J, et al. The risk, burden, and management of non-communicable diseases in cerebral palsy: a scoping review. Dev Med Child Neurol 2018;60:753-64.

8 Peterson MD, Ryan JM, Hurvitz EA, et al. Chronic conditions in adults with cerebral palsy. JAMA 2015;314:2303-5.

9 Blair E, Langdon K, Mclntyre S, et al. Survival and mortality in cerebral palsy: observations to the sixth decade from a data linkage study of a total population register and national death index. BMC Neurol 2019;19:111.

10 National Institute for Health and Care Excellence. Cerebral palsy in adults, 2019. Available: https://www.nice.org.uk/guidance/ng119 [Accessed 28 Jul 2020]

11 National Institute for Health and Care Excellence. Cerebral palsy in adults, 2020. Available: https://www.nice.org.uk/guidance/qs191 [Accessed 28 Jul 2020].

12 Northern Ireland Cerebral Palsy Register. Belfast: Queen's University Belfast. Available: https://www.qub.ac.uk/research-centres/Northern IrelandCerebralPalsyRegister/ [Accessed 28 Jul 2020].

13 Jonsson U, Eek MN, Sunnerhagen KS, et al. Cerebral palsy prevalence, subtypes, and associated impairments: a populationbased comparison study of adults and children. Dev Med Child Neurol 2019;61:1162-7.

14 Mutch L, Alberman E, Hagberg B, et al. Cerebral palsy epidemiology: where are we now and where are we going? Dev Med Child Neurol 1992;34:547-51.

15 Surveillance of Cerebral Palsy in Europe. Surveillance of cerebral palsy in Europe: a collaboration of cerebral palsy surveys and registers. surveillance of cerebral palsy in Europe (SCPE). Dev Med Child Neurol 2000;42:816-24.

16 Evans PM, Johnson A, Mutch L, et al. A standard form for recording clinical findings in children with a motor deficit of central origin. Dev Med Child Neurol 1989;31:119-20.

17 Palisano R, Rosenbaum P, Walter S, et al. Development and reliability of a system to classify gross motor function in children with cerebral palsy. Dev Med Child Neurol 1997;39:214-23.

18 McDowell BC, Kerr C, Parkes J. Interobserver agreement of the gross motor function classification system in an ambulant population of children with cerebral palsy. Dev Med Child Neurol 2007;49:528-33.

19 World Health Organisation. International statistical classification of diseases and related health problems 10th revision, 2019. Available: https://icd.who.int/browse10/2019/en [Accessed 7 Aug 2020].

20 Michelsen SI, Uldall P, Hansen T, et al. Social integration of adults with cerebral palsy. Dev Med Child Neurol 2006;48:643-9.

21 Public Health England. Multiple sclerosis: prevalence, incidence and smoking status - data briefing, 2020. Available: https://www.gov.uk/ government/publications/multiple-sclerosis-prevalence-incidenceand-smoking-status/multiple-sclerosis-prevalence-incidence-andsmoking-status-data-briefing [Accessed 28 July 2020].

22 Parkinson's UK. The incidence and prevalence of Parkinson's in the UK Results from the Clinical Practice Research Datalink Summary report, 2018. Available: https://www.parkinsons.org.uk/sites/default/ files/2018-01/CS2960\%20Incidence\%20and\%20prevalence\% 20report\%20branding\%20summary\%20report.pdf [Accessed 28 Jul 2020].

23 Morgan P, McGinley J. Gait function and decline in adults with cerebral palsy: a systematic review. Disabil Rehabil 2014;36:1-9.

24 Ryan JM, Peterson MD, Matthews A, et al. Noncommunicable disease among adults with cerebral palsy: a matched cohort study. Neurology 2019;93:e1385-96.

25 Bromham N, Dworzynski K, Eunson P, et al. Cerebral palsy in adults: summary of NICE guidance. BMJ 2019;364:1806. 